\title{
Tuberculosis of Tonsil and Its Diagnosis
}

\author{
Sushna Maharjan ${ }^{1 *}$, Puja Neopane ${ }^{2}$ and Ramesh Parajuli ${ }^{3}$ \\ ${ }^{1}$ Department of Pathology, Chitwan Medical College Teaching Hospital, Nepal \\ ${ }^{2}$ Department of Oral Medicine and Pathology, School of Dentistry, Health Sciences University of Hokkaido, Japan \\ ${ }^{3}$ Department of Department of Otorhinolaryngology, Chitwan Medical College Teaching Hospital, Nepal
}

Submission: April 22, 2017; Published: April 25, 2017

*Corresponding author: Sushna Maharjan, Department of Pathology, Chitwan Medical College Teaching Hospital (CMC-TH), P.O. Box 42, Bharatpur, Chitwan, Nepal, Email: sushnamaharjan74@gmail.com

Abstract

Tuberculosis (TB) is the common communicable disease worldwide. Extrapulmonary tuberculosis (EPTB) is found in only $10-15 \%$ of all TB cases. Tuberculosis of oral cavity and upper airway is rare, and TB of palatine tonsils is even rarer. Diagnosing EPTB such as tuberculosis of tonsil remains challenging because clinical samples obtained from relatively inaccessible sites may be paucibacillary which decreases the sensitivity of diagnostic tests. The tonsillar specimens should be obtained for both mycobacteriological and histopathological examinations. The measurement of biochemical markers in TB-affected pleural fluids such as adenosine deaminase or gamma interferon could be supportive tests for diagnosis. Molecular biology techniques such polymerase chain reaction may be helpful in rapid diagnosis as well as in paucibacillary cases.

Keywords: Biochemical markers; Diagnosis; Molecular biology techniques; Tuberculosis

Abbreviations: TB: Tuberculosis; EPTB: Extrapulmonary tuberculosis; HIV: human immunodeficiency virus; WHO: World Health Organization; AIDS: Acquired immune deficiency syndrome; PTB: pulmonary TB; ATDs: Antitubercular drugs; PCR: Polymerase Chain Reaction; ADA: Adenosine Deaminase; TST: Tuberculin Skin Test; IGRA: IFN- $\gamma$ Releasing Assay; IFN- $\gamma$ : Gamma Interferon

\section{Introduction}

Tuberculosis (TB) is the common communicable disease worldwide. It was identified in early 4th century as phthisis, lupus, and scrofula. In 1882, Koch's described the bacillus. There was an estimated 10.4 million new (incident) TB cases worldwide in 2015. Among these, 5.9 million (56\%) were men, 3.5 million (34\%) women and 1.0 million (10\%) children. People living with human immunodeficiency virus (HIV) accounted for 1.2 million (11\%) of all new TB cases. About 1.4 million TB deaths was estimated in 2015 and an additional 0.4 million deaths resulting from TB disease among people living with HIV. According to WHO, the majority of new cases of TB was reported from South East Asia. Six countries accounted for $60 \%$ of the new cases: India, Indonesia, China, Nigeria, Pakistan and South Africa [1]. Incidence of TB is in rising tendency in developed world because of the increasing incidence of drug resistance [2] among Tubercle bacilli, wide prevalence of acquired immune deficiency syndrome (AIDS) [3,4] and transglobal migration [4].

Although the number of TB deaths fell by $22 \%$ between 2000 and 2015, TB remained one of the top 10 causes of death worldwide in 2015 [1]. There are two types of clinical manifestation of tuberculosis- pulmonary TB (PTB) and extrapulmonary TB (EPTB). Most of the patients suffer from PTB. ЕРTB is known for TB involving organs other than the lungs (e.g., pleura, lymph nodes, abdomen, genitourinary tract, skin, joints and bones, or meninges) [5]. EPTB is found in only 10$15 \%$ of all TB cases [6]. Tuberculosis of oral cavity and upper airway is rare, and TB of palatine tonsils is even rarer.

\section{Incidence and route of infection of tonsillar TB}

Tonsillar tuberculosis is rare with an incidence of less than $5 \%$ [7].The incidence of tonsillar TB was relatively high in the pre-pasteurization era due to Mycobacterium bovis infection through the ingestion of unpasteurized milk of cow [8]. In 1963, Miller [9] concluded that with the advent of pasteurized milk the incidence of TB decreased. Tonsil is a lymphoid tissue located in a site where it is constantly exposed by infected sputum / saliva but the incidence of tonsillar TB has remained rather low. The probable reasons behind this low incidence could be [10]:
a) The antiseptic and cleansing action of saliva.
b) Presence of saprophytes in oral cavity making colonization of tuberculous bacilli rather difficult .
c) Thick protective stratified squamous epithelial surface 
covering of tonsil resistant to colonization by mycobacterium tuberculosis.

d) Inherent resistance of tonsil to tuberculosis.

After invent of highly effective antitubercular drugs (ATDs), incidence of tonsillar TB is reduced to zero, but its incidence is increasing nowadays as mentioned above. Tonsillar TB are commonly found in patients with poor host reaction due to alcoholism, HIV infection, and so forth. Poor dental hygiene, dental extraction, periodontitis, and leukoplakia are the predisposing factors for primary oral TB. It has been postulated that such infections are acquired by inhalation, with harbouring of disease in Waldeyer's ring as secondary form rather than primary form [11].

\section{Classification of tonsillar tuberculosis [12]:}

Irwin Moore's classified tonsillar TB into:

a) Primary tuberculosis of tonsil- TB of tonsil occurs without involvement of lungs

b) Secondary tuberculosis of tonsil- There is pulmonary involvement with presence of positive sputum smear in addition to tonsillar TB.

\section{Diagnosis}

\section{i. Mycobacterial stain and culture}

The culture of Mycobacterium tuberculosis organisms from a tonsillar specimen of the patient can make a definitive diagnosis of TB. However, Mycobacterial culture usually takes 2-8 weeks to receive the results, which is too slow to help treatment decisions [13]. Despite normal chest radiography findings, some ЕРTB patients have positive sputum culture results [14]. Bronchoscopic evaluation or sputum induction with nebulized hypertonic saline can increase diagnostic sensitivity $[15,16]$.

\section{ii. Biopsy}

The diagnosis of tonsillar TB depends on the histological evidence. There should be presence of epithelioid granulomas, caseous necrosis, Langhan giant cells and AFB positive test for histopathologic diagnosis. However, loss of host immune function can result in demonstrating greater suppurative response and less well-formed granulomas in histopathologic findings [17]. Diagnostic accuracy can be increased if the results of the histology and polymerase chain reaction (PCR) assays are combined with those of culture. Moreover, formalin used for preservation of biopsy specimens destroys the mycobacteria and prevents further culture confirmation. Hence, biopsy material for mycobacterial culture should be submitted fresh or in a small amount of sterile saline.

\section{iii. Examination of body fluid}

Tissue biopsy is the most effective method of diagnosing tonsillar TB but it is invasive. The more easily accessible body fluid, such as pleural fluid can be studied if the patient has associated primary pulmonary $\mathrm{TB}$, then it can often provide valuable diagnostic clue for diagnosis. Exudative fluid is found in tuberculous pleural fluid study with predominance of lymphocytes in about $90 \%$ of cases. Adenosine deaminase (ADA) measurement is one of the most widely used biomarkers in body fluids for the diagnosis of EPTB. ADA is an enzyme involved although possible false-negative and false-positive results should be considered [18-20].

\section{iv. Nucleic acid amplification test}

The nucleic acid amplification test, such as PCR has a major advantage, i.e., a rapid diagnosis can be made. The sensitivity could be improved by PCR because EPTB is a paucibacillary disease, as it can detect as few as 10 mycobacteria [21].

\section{v. Immunological tests}

There are some supportive methods for diagnosing tonsillar TB, such as Tuberculin skin test (TST) and IFN- $\gamma$ releasing assay (IGRA), but these have a limited diagnostic value. Interpretation of the result of TST reactivity can be complicated by crossreactivity with previous Bacille Calmette-Guerin vaccination or latent TB infection in countries where TB is common. Other factors like HIV infection, poor nutritional status, recent viral or bacterial infections, or vaccination with live virus can also reduce response to the TST. Similarly, IGRA cannot distinguish between latent infection and active pulmonary TB or EPTB. Thus, negative results cannot entirely exclude the disease [22].

\section{Conclusion}

The tonsillar specimens should be obtained for both mycobacteriological and histopathological examinations. The measurement of biochemical markers in TB-affected pleural fluids such as ADA or IFN- $\gamma$ releasing assay could be supportive tests for the diagnosis. Molecular biology techniques such PCR may be helpful in rapid diagnosis as well as in paucibacillary cases.

\section{References}

1. Global tuberculosis report (2016) World Health Organization.

2. Johnson R, Streicher EM, Louw GE, Warren RM, van Helden PD, et al. (2006) Drug resistance in Mycobacterium tuberculosis. Curr Issues Mol Biol 8(2): 97-111.

3. Swaminathan S, Narendran G (2008) HIV and tuberculosis in India. J Biosci 33(4): 527-537.

4. Corbett EL, Watt CJ, Walker N, Maher D, Williams BG et al. (2003) The growing burden of tuberculosis: Global trends and interaction with the HIV epidemic. Arch Intern Med 163: 1009-1021.

5. World Health Organization. Definitions and reporting framework for tuberculosis: 2013 revision (updated December 2014) Geneva: World Health Organization; 2013.

6. Patel AK, Thakrar SJ, Ghanchi FD (2011) Clinical and laboratory profile of patients with TB/HIV coinfection: A case series of 50 patients. Lung India 28: 93-96.

7. Wilkinson HF (1929) A study of ten thousand pairs of tonsils, with special reference to the presence of cartilage, bone, tuberculosis and 
bodies suggestive of Actinomycosis. Arch Otolaryngol 10(2): 127-151.

8. Anim JT, Dawlatly EE (1991) Tuberculosis of the tonsil revisited. West Afr J Med 10(2): 194-197.

9. Miller JFW, Seal RME, Taylor MD (1963) Tuberculosis in children, J \& A Churchill Ltd.

10. Janna U, Mukherjee S (2003) Tuberculosis of tonsil-a rare involvement. Indian J Otolaryngol Head Neck Surg 55(2): 119-120.

11. Gupta KB, Tandon S, Jaswal ST, Singh S (2001) Tuberculosis of the tonsil with unusual presentation. Indian J Tuberc 48: 223-224.

12. Balasubramanian T, Geetha R, Venkatesan U (2012) Secondary tuberculosis of tonsil case report and literature review. Online J Otolaryngol 2(1): 59-67.

13. (2013) Canadian Thoracic Society and The Public Health Agency of Canada and Licensors. Canadian tuberculosis standards. ( $7^{\text {th }}$ edn). Public Health Agency of Canada, Ottawa, USA.

14. Parimon T, Spitters CE, Muangman N, Euathrongchit J, Oren E, et al. (2008) Unexpected pulmonary involvement in extrapulmonary tuberculosis patients. Chest 134: 589-594.

15. Lee J, Lee SY, Choi KJ, Lim JK, Yoo SS, et al. (2013) Clinical Utility of CT-based bronchial aspirate TB-PCR for the rapid diagnosis of pleural tuberculosis. Tuberc Respir Dis 75: 150-156.
16. Conde MB, Loivos AC, Rezende VM, Soares SL, Mello FC et al. (2003) Yield of sputum induction in the diagnosis of pleural tuberculosis. Am J Respir Crit Care Med 167: 723-725.

17. de Noronha AL, Bafica A, Nogueira L, Barral A, Barral-Netto M (2008) Lung granulomas from Mycobacterium tuberculosis /HIV-1 coinfected patients display decreased in situ TNF production. Pathol Res Pract 204: 155-161.

18. Lee SJ, Kim HS, Lee SH, Lee TW, Lee HR, et al. (2014) Factors influencing pleural adenosine deaminase level in patients with tuberculous pleurisy. Am J Med Sci 348: 362-365.

19. Abrao FC, de Abreu IR, Miyake DH, Busico MA, Younes RN (2014) Role of adenosine deaminase and the influence of age on the diagnosis of pleural tuberculosis. Int J Tuberc Lung Dis 18: 1363-1369.

20. Liao YJ, Wu CY, Lee SW, Lee CL, Yang SS, et al. (2012) Adenosine deaminase activity in tuberculous peritonitis among patients with underlying liver cirrhosis. World J Gastroenterol 18(37): 5260-5265.

21. Manjunath N, Shankar P, Rajan L, Bhargava A, Saluja S, et al. (1991) Evaluation of a polymerase chain reaction for the diagnosis of tuberculosis. Tubercle 72(1): 21-27.

22. Lee JY (2015) Diagnosis and Treatment of extrapulmonary tuberculosis. Tuberc Respir Dis 78: 47-55.

\section{Your next submission with Juniper Publishers} will reach you the below assets

- Quality Editorial service

- Swift Peer Review

- Reprints availability

- E-prints Service

- Manuscript Podcast for convenient understanding

- Global attainment for your research

- Manuscript accessibility in different formats

( Pdf, E-pub, Full Text, Audio)

- Unceasing customer service

Track the below URL for one-step submission https://juniperpublishers.com/online-submission.php 